\title{
HUBUNGAN PENGETAHUAN HEIMLICH MANUVER PADA IBU DENGAN KETERAMPILAN PENANGANAN ANAK TODDLER YANG MENGALAMI CHOCKING
}

\author{
Relationship between Heimlich Maneuver Knowledge with Chocking \\ Response Competency among Mothers with Toddler
}

\section{Edita Refine Siahaan}

Akademi Perawat Bunda Delima, Bandar Lampung

E-mail: editasiahaan@bundadelimalampung.ac.id

\begin{abstract}
ABSTRAK
Pendahuluan: kelompok anak usia pertumbuhan toddler adalah anak-anak yang mengalami masa eksplorasi sering mengalami tersedak. Tersedak merupakan suatu kegawat daruratan yang sangat berbahaya, pengetahuan dan keterampilan ibu dalam penangan kedaruratan tersedak sangatlah penting. Tujuan: penelitian ini mertujuan untuk mengengkaji gambaran karakteristik ibu dan anak, pengetahuan ibu, dan kemampuan ibu menangani chocking. Lebih lanjut penelitian ini bertujuan untuk menganalisis hubungan pengetahuan ibu dengan kemampuan penanganan chocking. Metode: penelitian ini adalah penelitian kuantitatif dengan desain penelitian menggunakan metode cross sectional. Populasi dalam penelitian ini adalah ibu yang memiliki anak berusia 1 sampai 3 tahun yang terdata pada Puskemas satelit di kelurahan Tanjung Raya yang berjumlah 50 orang. Sampel dalam penelitian ini diambil dengan tekhnik sampling total sampling. Hasil: pengetahuan ibu-ibu dengan anak toddler tentang Heimlich Manuver didapati masih rendah. Terdapat hubungan yang signifikan antara tingkat pengetahuan ibu dengan kemampuan penanganan anak tersedang dengan nilai $p=0.000$. Diskusi: peran serta semua pihak tim kesehatan untuk meningkatkan pengetahuan ibu dalam penanganan anak tersedak sangatlah penting.
\end{abstract}

Kata kunci: Anak tersedak, Heimlich maneuver, Pengetahuan ibu

\begin{abstract}
Introduction: Children at toddler age groups are children who characterized with exploration behavior often experience choking. Choking is a very dangerous emergency situation, mother's knowledge and skills in handling emergency choking is very essential. Purpose: This study aims to explore the characteristics of mother and child, mother's knowledge, and the ability of mothers to handle chocking. Furthermore, this study aims to analyze the relationship between mother's knowledge and the ability to handle chocking. his research is a quantitative study with a research design using cross sectional method. Method: The population in this study were mothers with children aged 1 to 3 years who were recorded in a satellite health center in Tanjung Raya village, amounting to 50 people. The sample in this study was taken with a total sampling technique. Results: knowledge of mothers with toddlers about Heimlich Maneuver was found to be low. There is a significant relationship between the level of knowledge of mothers with the ability to handle children with $p=0,000$. Discussion: the participation of all parties in the health team to increase the knowledge of mothers in handling choking children is very important.
\end{abstract}

Keywords: Choking among toddler, Heimlich Maneuver Knowledge of the mothers

JURNAL

SKOLASTIK

KEPERAWATAN

VOL. 5, NO. 2

Juli - Desember 2019

ISSN: $2443-0935$

E-ISSN 2443 - 16990 


\section{PENDAHULUAN}

Kelompok anak usia pertumbuhan toddler adalah anak-anak yang berumur 1 sampai 3 tahun dimana anak pada usia mengalami masa eksplorasi lingkungan yang intensif, dimana anak berusaha mencari tahu bagaimana semua dapat terjadi dalam kehidupannya (Wong, 2009). Pada usia ini adalah usia krisis karena anak mulai ingin mengeksplorasi makanan yang ada di mulutnya, sehingga anak beresiko untuk tersedak.

Data dari Organisasi Kesehatan Dunia World Health Organization (WHO) pada tahun 2011 terdapat 17.537 kasus anak usia toddler (1-3 tahun) yang paling sering mengalami tersedak. Penyebab tersedak yang paling sering dijumpai pada anak-anak adalah karena makanan sekitar 59,5\% 31,4\% tersedak karena benda asing, dan sebesar $9,1 \%$ penyebab tersedak yang tidak diketahui. Di Indonesia data yang diperoleh di RSUD dr. Harjono, Jawa Timur terdapat 157 kasus tersedak pada tahun 2009 dan di tahun berikutnya sebanyak 112 kasus (Novitasari, 2016).

Berdasarkan data dari Yayasan Ambulan Gawat Darurat 118 (2015) anak dengan usia $<5$ tahun mengalami kematian $90 \%$ disebabkan oleh sumbatan benda asing pada saluran jalan nafas.

Selaras dengan data tersebut, data dari American Academy of Pediatrics (2010) memaparkan bahwa penyebab utama dari morbiditas dan mortalitas anak di bawah 3 tahun adalah tersedak. Makanan, minuman, balon, koin yang berserakan di lantai adalah menjadi penyebab tersedak paling sering dan bahkan menyebabkan kematian.

Tersedak merupakan suatu kegawat daruratan yang sangat berbahaya, karena dalam beberapa menit akan terjadi kekurangan oksigen secara umum dan menyeluruh sehingga hanya dalam hitungan menit dapat kehilangan refleks napas, denyut jantung dan dapat mengalami kematian (Sarah, 2015). Pengetahuan dan keterampilan orangtua dalam penanganan kedaruratan tersedak pada anak sangatlah penting.

Hasil wawancara terhadap orang tua yang memiliki anak usia 1-3 tahun yang tinggal di daerah Tanjung Raya, didapatkan hasil bahwa terdapat 40 orang tua tidak memahami tentang penanganan jika anak tersedak. Berdasarkan informasi yang diperoleh semua orang tua hanya memberikan minum saat anaknya tersedak. Orang tua tidak mengetahui jika implementasi dalam memberikan minum saat anak tersedak tidak tepat. Dengan demikian dapat disimpulkan bahwa, seluruh orang tua belum mengetahui penanganan anak jika anak tersedak dengan baik dan benar.

Pengetahuan penanganan kedaruratan yang tepat pada anak tersedak terdiri dari tiga tekhnik yaitu penekanan dada (chest trust), hentakan perut (manuver heimlich), dan tepukan punggung (back blow). Pada usia anak satu sampai lima tahun serta orang dewasa, semua tekhnik dapat digunakan sesuai dengan keahlian penolong (YAGD 118, 2015). 
Penelitian ini bertujuan untuk mengengkaji gambaran karakteristik ibu dan anak, pengetahuan ibu, dan kemampuan ibu menangani chocking. Lebih lanjut penelitian ini untuk menganalisis hubungan pengetahuan ibu dengan kemampuan penanganan chocking.

\section{METODE}

Penelitian ini adalah penelitian kuantitatif dengan desain penelitian menggunakan metode cross sectional. Penelitian ini dilakukan di Wilayah Kelurahan Tanjung Raya, Bandar Lampung. Populasi dalam penelitian ini adalah ibu yang memiliki anak berusia 1 sampai 3 tahun yang terdata pada Puskemas satelit di kelurahan Tanjung Raya yang berjumlah 50 orang. Sampel dalam penelitian ini diambil dengan tekhnik sampling total sampling. Kriteria inklusi berikut ditetapkan ditetapkan dalam melibatkan setiap responden:

1. Responden orang tua saat penelitian dilakukan setuju untuk ikut dalam mengisi kuesioner.

2. Orang tua anak menanda tangani persetujuan inform consent sebagai subjek dalam penelitian ini.

3. Orang tua yang mempunyai anak toodler dan di wilayah tanjung raya bandar lampung.

4. Mengikuti SOP (Standar Operasional Prosedur) penelitian yang diberikan secara keseluruhan oleh peneliti.

Data dikumpulkan selama tiga hari, dari tanggal 01 Oktober 2019 sampai 03 Oktober 2019. Setelah diberikannya surat uji etik penelitian dari KEPK
Akper Bunda Delima Bandar Lampung dan ijin ke Kesbangpol Kota Bandar Lampung, peneliti kemudian berkoordinasi dengan pihak Puskesmas Satelit Bandar Lampung. Dalam pemberian inform consent satu minggu sebelum penelitian kepada orang tua dan di bantu oleh tim mahasiswa Akper Bunda Delima memberikan kuesioner ke ibu di Wilayah Kelurahan Tanjung Raya, Bandar Lampung.

Instrumen pengumpulan data penelitian ini adalah menggunakan lembar kuesioner tentang pengetahuan heimlich manuver (WHO, 2010) kepada ibu serta menggunakan lembar observasi kemampuan pelaksanaan heimlich manuver pada anak. Analisis univariat digunakan untuk mendeskripsikan variable atribut serta karakteristik masing-masing variabel yang diteliti. Analisis bivariat digunakan untuk menganalisa hubungan antara pengetahuan Ibu tentang heimlich manuver dengan kemampuan menangani anak toddler jika tersedak maka.

\section{HASIL}

\section{Data Demografi}

Berdasarkan tabel 1 menunjukkan bahwa dari 50 responden hampir setengahnya responden usia 1-2 tahun yaitu 20 anak $(40,0 \%)$ dan usia 2-3 tahun sebanyak 30 anak (60,0\%). Jenis kelamin anak toodler didominasi perempuan 26 anak (52\%) dan lakilaki 24 anak (48\%). Pekerjaan orang tua sebagian besar adalah IRT sebanyak 38 orang tua $(76 \%)$ dan 
karyawan swasta 20 orang tua (10\%), serta PNS 2 orang (4\%). Pendidikan orang tua sebagian besar lulusan SMA sebanyak 33 orang (66\%), Universitas 7 orang (8\%), SMP 10 orang (20\%). Penanganan anak jika anak tersedak, orang tua tidak mengerti apa yang akan dilakukan mendominasi sebesar 46 orang tua $(92 \%)$ dan yang mengerti hanya 4 orang tua $(8 \%)$.

Tabel 1. Data Demografi di Puskesmas Satelit Kelurahan Tanjung Raya $(n=50)$

\begin{tabular}{|c|c|c|}
\hline Karakteristik & Frekuensi (n) & Persentase $(\%)$ \\
\hline \multicolumn{3}{|l|}{ Jenis Kelamin Anak } \\
\hline a. Laki-laki & 24 & 48 \\
\hline b. Perempuan & 26 & 52 \\
\hline \multicolumn{3}{|l|}{ Pekerjaan orang tua } \\
\hline a. IRT & 38 & 76 \\
\hline b. Karyawan swasta & 10 & 20 \\
\hline c. PNS & 2 & 4 \\
\hline \multicolumn{3}{|l|}{ Pendidikan orang tua } \\
\hline a. SMP & 10 & 20 \\
\hline b. SMA & 33 & 66 \\
\hline c. Universitas & 7 & 14 \\
\hline \multicolumn{3}{|l|}{ Umur orang tua } \\
\hline a. $20-30$ & 21 & 42 \\
\hline b. $31-40$ & 23 & 46 \\
\hline c. $41-50$ & 6 & 12 \\
\hline \multicolumn{3}{|l|}{ Sumber infomasi } \\
\hline a. $\mathrm{TV}$ & 42 & 84 \\
\hline b. Surat Kabar & 1 & 2 \\
\hline c. Media sosial & 7 & 14 \\
\hline \multicolumn{3}{|l|}{ Tempat pertolongan tersedak } \\
\hline a. Puskesmas & 44 & 88 \\
\hline b. Klinik & 4 & 8 \\
\hline c. Rumah Sakit & 2 & 4 \\
\hline Perilaku jika anak tersedak & & \\
\hline a. Dibiarkan saja & 14 & 28 \\
\hline
\end{tabular}




\begin{tabular}{|rll} 
b. Diberi minum & 31 & 62 \\
c. Diberi makan & 3 & 6 \\
\hline Penangan anak jika tersedak & & \\
a. Ya mengerti & 4 & 08 \\
b. Tidak mengerti & 46 & 92
\end{tabular}

Umur anak

a. $1-2 \quad 20 \quad 40$

b. $2-3 \quad 30 \quad 60$

Penyebab anak tersedak

a. Makanan $\quad 30 \quad 60$

b. Minuman Buble $\quad 5 \quad 10$

$\begin{array}{lll}\text { c. Benda } & 15 & 30\end{array}$

Logam/Mainan

Berdasarkan tabel 1 menunjukkan bahwa dari 50 responden hampir setengahnya responden usia 1-2 tahun yaitu 20 anak $(40,0 \%)$ dan usia 2-3 tahun sebanyak 30 anak $(60,0 \%)$. Jenis kelamin anak toodler didominasi perempuan 26 anak (52\%) dan lakilaki 24 anak (48\%). Pekerjaan orang tua sebagian besar adalah IRT sebanyak 38 orang tua $(76 \%)$ dan karyawan swasta 20 orang tua (10\%), serta PNS 2 orang (4\%). Pendidikan orang tua sebagian besar lulusan SMA sebanyak 33 orang $(66 \%)$, Universitas 7 orang (8\%), SMP 10 orang (20\%). Penanganan anak jika anak tersedak, orang tua tidak mengerti apa yang akan dilakukan mendominasi sebesar

46 orang tua (92\%) dan yang mengerti hanya 4 orang tua $(8 \%)$.

\section{Gambaran Pengetahuan ibu dalam penanganan chocking pada anak}

Tabel 2 menunjukkan bahwa tingkat pengetahuan ibu dalam penanganan chocking dengan pengetahuan baik sebesar 1 orang $(2 \%)$, pengetahuan sedang 12 orang (24\%) serta pengetahuan ibu yang kurang 37 orang (74\%). Hasil uji statistik menunjukkan Penanganan anak jika anak tersedak, orang tua tidak mengerti apa yang akan dilakukan mendominasi sebesar 46 orang tua (92\%) dan yang mengerti hanya 4 orang tua $(8 \%)$.

Hasil uji statistik menunjukkan bahwa di indikasikan secara persentase lebih banyak orang tua tidak mengerti apa yang akan dilakukan jika anak tersedak. Notoadmodjo (2012) menyatakan pengetahuan merupakan domain yang sangat penting dalam membentuk tindakan individu. Faktor yang mempengaruhi pengetahuan seorang ibu dipengaruhi oleh pendidikan orang tua, pekerjaan orang tua, usia orang tua, informasi, pengalaman lingkungan serta sosial budaya. 
Tabel 2. Distribusi Frekuensi Pengetahuan ibu dalam penanganan chocking

\begin{tabular}{lll}
\hline $\begin{array}{l}\text { Kategori } \\
\text { Pengetahuan }\end{array}$ & $\begin{array}{l}\text { Frekuens } \\
\mathrm{i}(\mathrm{n})\end{array}$ & $\begin{array}{l}\text { Persenta } \\
\text { se }(\%)\end{array}$ \\
\hline Baik & 1 & 2,0 \\
\hline Sedang & 12 & 24,0 \\
\hline Kurang & 37 & 74,0 \\
\hline
\end{tabular}

Faktor yang mempengaruhi adalah pendidikan ibu, pada penelitian ini pendidikan ibu mendominasi lulusan SMA sebesar 33 orang (66\%), SMP 10 orang $(20 \%)$ serta Universitas 7 orang (14\%). Pendidikan orang tua sangat dipengaruhi dengan tingkat pengetahuan, pendidikan diperlukan untuk menunjang kesehatan anak khususnya penanganan chocking pada anak untuk meningkatkan kualitas hidup (Rahayu, 2014).

Faktor yang mempengaruhi selanjutnya adalah pekerjaan orang tua, pekerjaan orang tua dalam penelitian ini adalah mendominasi adalah IRT (Ibu Rumah Tangga) sebesar 38 orang (76\%), karyawan swasta 10 orang (20\%) dan PNS 2 orang (4\%). Menurut Nursalam (2013) pekerjaan orang tua sangat mempengaruhi pengetahuan seorang ibu, paparan pekerjaan diluar memberikan peluang langsung kepada ibu dalam informasi paparan dimedia sosial dalam pengetahuan ibu khususnya pengetahuan masalah penanganan anak terhadap masalah chocking pada anak.
Faktor selanjutnya adalah usia orang tua, dalam penelitian ini usia orang tua sangat mempengaruhi pengetahuan ibu. Usia 31-40 tahun (46\%) mendominasi usia ibu dalam penelitian pengetahuan ibu dalam penanganan chocking pada anak. Semakin tinggi usia orang tua, semakin sulit pengetahuan $\mathrm{ibu}$ dalam menerima edukasi. Hal ini sejalan dengan teori Notoadmodjo (2012).

Faktor selanjutnya adalah informasi, informasi dalam penelitian ini, Hasil kuesioner dalam penelitian ini ibu mendapatkan paparan informasi melalui media televisi sebanyak 42 orang $(84 \%)$, surat kabar 1 orang $(2 \%)$, Media sosial 7 orang (14\%). Dari hasil kuesioner ini menunjukkan ibu mendominasi mendapatkan informasi mendominasi melalui media televisi. Faktor terakhir adalah pengalaman lingkungan ibu serta sosial budaya. Menurut Notoadmodjo (2012) pengalamaman lingkungan mempengaruhi seseorang untuk cepat dapat menerima pengetahuan. Dalam penelitian ini ibu tinggal dikawasan lingkungan tanjung raya yang dekat dengan pusat kota, ini memudahkan akses ibu dalam memudahkan pengetahuan ibu dalam penanganan chocking pada anak toodler.

\section{Gambaran keterampilan ibu dalam penanganan chocking pada anak}

Berdasarkan Tabel 3 menunjukkan sebagian besar kategori keterampilan 40 orang $(80,00 \%)$ dan ketermpilan baik sebanyak 10 orang $(20,00 \%)$. Hasil uji statistik menunjukkan bahwa anak mengalami tersedak mendominasi dikarenakan makanan 
sebanyak 30 anak (60\%), minuman buble sebanyak 5 anak (10\%) dan benda logam/mainan sebanyak 15 anak (30\%). Ini menunjukkan bahwa makanan menjadi faktor penyebab terbesar anak mengalami tersedak.

Tabel 3. Distribusi frekuensi keterampilan ibu dalam penanganan chocking pada anak

\begin{tabular}{lll}
\hline $\begin{array}{l}\text { Kategori } \\
\text { keterampilan }\end{array}$ & $\begin{array}{l}\text { Frekuensi } \\
(\mathrm{n})\end{array}$ & $\begin{array}{l}\text { Persentas } \\
\mathrm{e}(\%)\end{array}$ \\
\hline $\begin{array}{l}\text { Keterampilan } \\
\text { kurang }\end{array}$ & 40 & 80 \\
\hline $\begin{array}{l}\text { Keterampilan } \\
\text { baik }\end{array}$ & 10 & 20 \\
\hline Total & 50 & 100 \\
\hline
\end{tabular}

Dalam penelitian ini hasil kuesioner menunjukkan ibu adalah orang yang pertama mengetahui anak dalam masalah chocking, dari 50 hasil kuesioner sebanyak 50 orang menjawab ibu yang membawa anak ke pusat kesehatan masyarakat (Puskesmas) jika anak mengalami masalah tersedak.

\section{Hubungan pengetahuan heimlich manuver pada ibu dengan keterampilan penanganan chocking pada anak}

Berdasarkan Tabel 4 di bawah terlihat bahwa ada hubungan antara pengetahuan ibu heimlich manuver pada ibu dengan keterampilan penanganan anak toodler yang mengalami chocking. Berdasarkan hasil (Uji Chi Square Tests) terdapat hubungan yang signifikan antara pengetahuan ibu heimlich manuver pada ibu dengan keterampilan penanganan anak toodler yang mengalami chocking dengan signifikansi $p=0,000$.

Tabel 4. Hasil uji Chi-square Tests

\begin{tabular}{|c|c|c|c|}
\hline & Value & $\mathrm{df}$ & $\begin{array}{l}\text { Significan } \\
\text { ce }\end{array}$ \\
\hline $\begin{array}{ll}\text { Pearson } & \text { Chi } \\
\text { Square } & \end{array}$ & $\begin{array}{l}50.000 \\
a\end{array}$ & 2 & 0,000 \\
\hline Likelihood Ratio & 57.306 & 2 & 0,000 \\
\hline $\begin{array}{l}\text { Linear-by-Linear } \\
\text { Association }\end{array}$ & 45.256 & 1 & 0,000 \\
\hline
\end{tabular}

\section{PEMBAHASAN}

Tersedak merupakan kondisi gawat darurat yang harus cepat ditangan, jika tidak cepat ditangani anak akan mengalami masalah kekurangan oksigen dan dapat mengalami kematian pada anak (Knapp, 2007). Faktor-faktor yang mempengaruhi anak tersedak yang terbesar adalah makanan (kacang-kacangan), minuman bublle, benda mainan atau logam (Greenberg, 2007). Makanan kacang-kacangan adalah konsumsi yang paling sering dikonsumsi oleh anak toddler dan ini memicu anak mudah tersedak, dan jika tidak ditangani dengan baik memicu kekurangan oksigen bahkan henti napas dan bisa mengalami kematian jika tidak ditangani secara cepat dan benar(Greenberg, 2005). Faktor kedua yang menyebabkan anak mudah tersedak adalah minuman bublle. Minuman bublee adalah minuman yang sering dikonsumsi oleh anak- 
anak hingga dewasa. Tetapi pada anak toddler sulit mengunyah bublle karena ukuran yang besar dan kenyal, dan ada menghindari pake sedotan sehingga dapat mengalami anak tersedak dan aspirasi paru saart mengkonsumsi bublle (Sally Kuzemchack, 2019).

Upaya untuk meningkatkan agar anak tidak tersedak adalah dengan pemberian edukasi dengan cara mengajarkan ketrampilan heimlich manuver kepada ibu. Ibu adalah orang terdekat pada anak sehingga ibu dapat mencegah agar anak tidak mengalami masalah kegawat daruratan pada anak tersedak. Karena jika dibiarkan dapat mengalami bahaya, tersedak, henti napas bahkan sampai mengalami kematian (Abdul Kadir, 2018).

Hasil analisis penelitian ini menunjukkan bahwa ada hubungan antara pengetahuan ibu heimlich manuver pada ibu dengan keterampilan penanganan anak toodler yang mengalami chocking. Berdasarkan hasil (Uji Chi Square Tests) terdapat hubungan yang signifikan antara pengetahuan ibu heimlich manuver pada ibu dengan keterampilan penanganan anak toodler yang mengalami chocking dengan signifikansi $p=0,000$. Hasil penelitian ini menunjukkan bahwa pengetahuan ibu dapat melalui penglihatan, mendengar dan pengalaman masa lalu (Hatice, 2009). Kaitanya dengan keterampilan heimlich manuver dapat dilakukan ibu ketika ada masalah dirumah atau dimasyarakat jika ada kasus anak tersedak.

Tindakan pertolongan pertama pada anak tersedak merupakan langkah yang harus dilakukan oleh ibu yaitu heimlich manuver. Heimlich manuver adalah memberikan hentakan pada dada atau perut kemudian meminta anak untuk membatukkan dengan keras agar benda asing atau makanan bisa keluar (Iskandar, 2012). Kaitannya dengan peran perawat anak di tatanan komunitas, harus bersikap pro aktif dengan melakukan edukasi di masyarakat secara rutin dan kontinyu sehingga keterampilan heimlich manuver ini dapat tersosialisasi oleh masyarakat khususnya kelurahan tanjung raya.

\section{KESIMPULAN}

Berdasarkan hasil penelitian ini dapat dibuat kesimpulan sebagai berikut:

1. Pengetahuan heimlich manuver pada ibu dengan keterampilan penanganan anak toodler yang yang mengalami chocking adalah pengetahuan ibu dengan baik sebanyak 1 orang (2\%), pengetahuan ibu sedang sebanyak 12 orang (24\%) serta pengetahuan ibu kurang sebanyak 37 orang (74\%).

2. Gambaran karakteristik ibu adalah adalah IRT sebanyak 38 orang tua $(76 \%)$ dan karyawan swasta 20 orang tua (10\%), serta PNS 2 orang $(4 \%)$. Pendidikan orang tua sebagian besar lulusan SMA sebanyak 33 orang $(66 \%)$, Universitas 7 orang (8\%), SMP 10 orang (20\%). Gambaran karakteristik anak adalah 50 responden anak hampir setengahnya responden usia 1-2 tahun yaitu 20 anak $(40,0 \%)$ dan usia 2-3 tahun sebanyak 30 anak $(60,0 \%)$. Jenis kelamin anak 
toodler didominasi perempuan 26 anak (52\%) dan laki-laki 24 anak (48\%). Serta gambaran kemampuan ibu dalam penanganan chocking mendominasi tidak mengerti penanganan chocking sebanyak 46 orang tua (96\%).

3. Terdapat hubungan pengetahuan heimlich manuver pada ibu dengan keterampilan penanganan anak toodler yang yang mengalami chocking dengan signifikan $p$ $=0,000$.

\section{Saran}

Saran-saran yang dapat disampaikan oleh penulis berdasarkan hasil penelitian ini adalah:

1. Diharapkan perawat puskesmas terdekat diharapkan menjadi edukator dan fasilitator kepada orang tua khususnya anak-anak toddler tentang pentingnya penanganan segera chocking dirumah atau dilingkungan diluar rumah dengan cara mempraktekan tekhnik heimlich manuver pada anak toddler dengan memberikan edukasi secara kontinu dalam waktu tiga bulan sekali serta melakukan evaluasi kepada masyarakat di daerah Kelurahan Tanjung Raya.

2. Diharapkan orang tua dapat meningkatkan pengetahuan edukasi penanganan chocking dengan aktif terlibat pada saat aktivitas, orang tua juga diharapkan meningkatkan pengetahuan dengan aktif bertanya dan konsultasi kepada petugas kesehatan serta memanfaatkan media elektronik sebagai media informasi, dan dapat mengaplikasikan tekhnik heimlich manuver di rumah, di lingkungan sekitar rumah dan di masyarakat. Diharapkan dengan penelitian ini juga orang tua anak toddler dapat memilih jenis makanan yang tidak membuat anak tersedak, dan orang tua dapat mengaplikasikanya secara berkelanjutan.

3. Pada penelitian ini baru dilakukan pada waktu secara crossectional dengan usia yang berbeda (toodler) jumlah sampel yang lebih banyak, diharapkan peneliti selanjutnya dapat melakukan penelitian yang sama dengan melanjutkan usia yang berbeda, dengan jumlah sampel yang lebih banyak dengan waktu yang longitudinal serta melakukan jenis penelitian quasy eksperimen.

\section{DAFTAR PUSTAKA}

Abdul kadir (2018). Pertolongan pertama saat anak tersedak.Jakarta: Hai Bunda. Diakses tanggal 1 Mei 2019. (https://www.haibunda.com/pare nting/20181022102141-6026976/pertolongan-pertama-saatanak-tersedak).

Agung (2004). Metodologi penelitian sosial 2. Jakarta: PT.Gramedia Pustaka Utama.

Allender \& $\quad$ Spradley.
Community $\begin{aligned} & \text { health } \\ & \text { nursing }\end{aligned}$
concept and practice.

American Academy of Pediatrics (2011). Chocking prevention and first aid for infants and children. 
American Heart Association (2015). Prevention of chocking among. American Academy of Pediatric 601-607

Arikunto. (2010). Prosedur penelitian - suatu pendekatan praktik. Jakarta: Rineka Cipta.

Arikunto. (2012). Prosedur penelitian - suatu pendekatan praktik. Jakarta: Rineka Cipta.

Armstrong. (2006). A Handbook of Human Resource Management Practice. $10 \quad$ Edition. London:Kogan Page Limited.

Creswell. (2015). Penelitian dan desain riset. (Edisi3). Yogyakarta: Pustaka Pelajar.

Dharma, (2011). Metodologi penelitian keperawatan. Depok: Trans Info Media.

Edwina. (2010). Pertolongan pertama bedah kritis. Di akses tanggal 1 Juni 2019.

Hastono. (2007). Analisis data kesehatan.Depok: $\quad$ Fakultas Kesehatan

Hockenberry \& Wilson. (2013). Essential of pediatric nursing. St louis. Mosby Year Book.

Fano et all (2019). Perception of chocking injury risk among healthcare students diakseshttps://www.researchgate .net/publication/332450176_Perc eption_of_Choking_Injury_Risk Among_Healthcare_Students
FKUI. (2015). Modul bantuan hidup dasar dan penanganan tersedak. Jakarta:Universitas Indonesia.

Knapp. (2007). American Academy of Pediatric Committee on Pediatric Emergency Medicine. Death of child in the emergency departement. American Academy of Pediatric, 1432.

Irianto. (2014). Gizi seimbang dalam kesehatan reproduksi. Bandung:Alfabeta.

Iskandar. (2012). Hubungan tingkat pengetahuan dengan perilaku ibu tentng pertolongan pertama pada anak tersedak di Boyolali Ngemplak di akses http://digilib.stikeskusumahusad a.ac.id/files/disk1/26/01-gdlchlivisiac-1282-1-chlivisi-a.pdf

Greenberg. (2007). The fear of chocking. Diakses 1 juli 2019 https://www.ncbi.nlm.nih.gov/pu $\underline{\mathrm{bmed} / 3340701}$

Kemenkes (2014). Rencana Strategis Kementerian Kesehatan Republik Indonesia Tahun 20152019. Jakarta: Kemenkes RI.

LPPM Stikes A yani (2015). Pedoman penulisan dan petunjuk tesis program studi ilmu keperawatan. Cimahi: LPPM Stikes A.Yani.

Rahayu. (2014). Pengaruh pendidikan kesehatan terhadap tingkat pengetahuan orang tua dalam menangani anak tersedak di desa 
kedungsoka puloampel Serang, Banten.

Mubarak. (2007). Promosi kesehatan:sebuah pengantar proses belajar mengajar dalam pendidikan. Yogyakarta:Graha ilmu.

Notoatmodjo. (2010). Promosi kesehatan teori dan ilmu perilaku. Jakarta: PT Rineka Cipta.

Notoatmodjo. (2012). Promosi kesehatan teori dan aplikasi. Jakarta:PT Rineka Cipta.

Novitasari. (2016). Pengaruh tentang pendidikan kesehatan tentang penanganan anak tersedak benda asing pad balita terhadap selfefficacy di posyandu desa pelem Magetan.

Nursalam. (2014). Metodologi riset keperawatan. Jakarta: Sagung Seto

Polit, D.F., \& Hungler, B.P. (1999). Nursing research: Priciples and methods. Fourth edition. Philadelpia: Lippincott.

Polit, D.F., \& Beck. (2012). Nursing research: Priciples and methods. Fourth edition. Philadelpia: Lippincott.

Polit. (2012). Nursing research generating and assessing evidence for nursing practice.Lippincott Williams \& Wilkins.(page. 152-171).
Rahmawati dan Suryani. (2019). Pengalaman ibu dalam penanganan anak tersedak di posyandu dusun kalongan di Bandung. Di akses jurnal 1 Juni 2019.

Sari dan Wulandini. (2018) Perilaku ibu dalam pertolongan pertama saat tersedak pada anak usia toodler. Diakses tanggal 1 Mei 2019.

Sally. (2019). Jakarta:Hai bunda. Diakses 1 Juni 2019 https://www.haibunda.com/paren ting/20190730123124-6050746/boba-di-bubble-tea-bisabikin-anak-tersedak-sampaisusah-napas

Sastroasmoro. (2011). Dasar-dasar metodologi penelitian klinis. Jakarta:Sagung seto.

SeattleChildrensHospitals.(2018).http: //www.healthierhospitals.org/site s/default/files/IMCE/seattle_chil drens_hospital.pdf Diakses tanggal 1 Mei 2019.

Siregar. (2013). Metode penelitian kuantitatif. Jakarta:Kencana Prenadamedia Group.

Sopiyudin (2012). Statistik untuk kedokteran dan kesehatan. Jakarta: Salemba medika.

Sopiyudin (2014). Penelitian diagnostik dasar-dasar teoritis dan aplikasi dengan program spss dan stata. Jakarta: Salemba Medika. 
Sugiyono. (2014). Metode penelitian kuantitatif dan kualitatif dan $r$ and $d$. Bandung:Alfabeta.

Sulfiana. (2015).Hubungan tingkat pengetahuan ibu dengan ibu tentang pertolongan pertama pada anak tersedak di semarang. Skripsi, Semarang. Di akses 1 April 2019.

Sutanto. (2007). Analisis data kesehatan. Fakultas kesehatan masyarakat: Universitas Indonesia.

Tomey \& Alligood. (2014). Nursing theorist and their work.Ninth Edition. Mosby. (page 396-406).
WHO. (2009). World Health Organization Prehospital trauma care system.Page 1-3. Diakses 1 juli 2019.

Wong. et al (2009). Buku AjarKeperawatan pediatrik. Volume: 2. Edisi 6. Jakarta: EGC.

Yayasan Ambulan Gawat Darurat 118 (2015). Basic Trauma Cardiac Life Suport. Jakarta.

Yuliati (2010). Hubungan pengetahuan ibu dalam pertolongan pertama saat tersedak pada anak usia toodler. Diakses tanggal 1 April 2019. 